\title{
Preparation and Bond Properties of Thermal Barrier Coatings on Mg Alloy with Sprayed Al or Diffused Mg-Al Intermetallic Interlayer
}

\author{
Xizhi Fan, Ying Wang, Binglin Zou, Lijian Gu, Wenzhi Huang, and Xueqiang Cao
}

(Submitted April 8, 2013; in revised form July 16, 2013)

\begin{abstract}
Sprayed Al or diffused Mg-Al layer was designed as interlayer between the thermal barrier coatings (TBCs) and Mg alloy substrate. The effects of the interlayer on the bond properties of the coats were investigated. Al layers were prepared by arc spraying and atmospheric plasma spraying (APS), respectively. Mg-Al diffused layer was obtained after the heat treatment of the sprayed sample (Mg alloy with APS Al coat) at $400{ }^{\circ} \mathrm{C}$. The results show that sprayed Al interlayer does not improve the bond stability of TBCs. The failure of the TBCs on Mg alloy with Al interlayer occurs mainly due to the low strength of Al layer. Mg-Al diffused layer improves corrosion resistance of substrate and the bond interface. The TBCs on Mg alloy with Mg-Al diffused interlayer shows better bond stability than the sample of which the TBCs is directly sprayed on Mg alloy substrate by APS.
\end{abstract}

Keywords bond stability, interlayer, magnesium alloy, TBCs

\section{Introduction}

$\mathrm{Mg}$ alloys are the lightest materials among those metals used for structural or mechanical applications (Ref 1). They also have many excellent properties such as high specific tensile strength, good stiffness, and vibration absorption (Ref 2, 3). Therefore, Mg alloys have potential applications in automobiles, electronic products, aerospace, etc. (Ref 4, 5). Unfortunately, Mg alloys have low melting point, poor wear resistance, and high chemical activity that have limited their widespread applications. Several surface coating technologies have been developed to improve the corrosion resistance, wear resistance, and thermal resistance of $\mathrm{Mg}$ alloys, such as electroless plating, conversion coatings, anodizing, gas-phase deposition, and thermal spraying (Ref 6). Among various surface coating treatments, thermal spraying is considered to be a relatively effective choice, as it can provide $\mathrm{Mg}$ alloy substrates with various coatings that have the desired properties of good corrosion, wear resistance, and thermal resistance.

Thermal barrier coatings (TBCs), typically comprising MCrAlY ( $\mathrm{M}=\mathrm{Ni}, \mathrm{Co})$ bond coat and yttria-stabilized

Xizhi Fan, Lijian Gu, and Wenzhi Huang, State Key Laboratory of Rare Earth Resources Utilization, Changchun Institute of Applied Chemistry, Chinese Academy of Sciences, Changchun 130022, Jilin China and Graduate School of Chinese Academy of Sciences, Beijing 100049, China; Ying Wang, Binglin Zou, and Xueqiang Cao, State Key Laboratory of Rare Earth Resources Utilization, Changchun Institute of Applied Chemistry, Chinese Academy of Sciences, Changchun 130022, Jilin China Contact e-mail: xcao@ciac.jl.cn. zirconia (YSZ) top coat, have low thermal conductivity and excellent surface properties (Ref 7-9). They are widely used to increase the operation temperature of systems such as gas turbines and diesel engines. In our previous studies (Ref 10), MCrAlY bond coat and 8YSZ top coat were successfully deposited on rare earthmagnesium alloy MB26 by atmospheric plasma spraying (APS). TBCs have an effective protection for $\mathrm{Mg}$ alloy.

During deposition of TBCs on $\mathrm{Mg}$ alloy substrate by APS, plasma flame has an obvious thermal effect on the substrate. A heat-affected layer (HAL) which includes re-melted zone and oxidized surface would grow on top of $\mathrm{Mg}$ alloy substrate. The re-melted zone is conducive to the strong occlusion between coat and substrate. However, the oxidation layer of the $\mathrm{Mg}$ alloy substrate is porous and fragile, and it has an unfavorable effect on the bond strength of the coat. Besides, 8YSZ top coat, MCrAlY bond coat and $\mathrm{Mg}$ alloy substrate have different thermomechanical properties. The property mismatch, together with the applied temperature gradient, usually results in thermal stress at the interfaces. The stress can be large enough to initiate surface and interface cracks (Ref 11). With the penetration of electrolyte into the interface through the cracks and pores, the substrate would be corroded. The corrosion of substrate at the interface reduces the bond strength of coat. Cyclic application of thermal shocks can cause the cracks to propagate along the bonding interface under the combined effect of substrate corrosion and thermal stress, resulting in delamination or spallation of the coating and loss of protection to the substrate. Therefore, the bond interface (mainly the interface between substrate and coat) properties (such as oxidation, corrosion, and thermo-physical properties) and the coat structure have an important impact on the bond stability of the thermal-sprayed TBCs.

In order to obtain the TBCs on $\mathrm{Mg}$ alloy with excellent bond stability, the bond interface and the coat structure 
should be improved. Several investigations over the past decade have reported the beneficial effects of employing functionally graded materials (FGMs) in the applications involving high temperature gradients (Ref 12). It is also reported that the bond strength and thermal shock resistance of plasma-sprayed functionally graded MCrAlY/ YSZ coatings were superior to that of a monolithic coating (Ref 13). Thus, one method of enhancing the resistance to thermal stress damages in TBCs is to produce a compositionally graded structure. Considering the thermal expansion coefficient (TEC) matching of this coat system and the chemical compatibility between the coat and $\mathrm{Mg}$ alloy substrate, an appropriate metallic interlayer with moderate TEC should be applied.

$\mathrm{Al}$ is considered as a good candidate for $\mathrm{Mg}$ alloy surface coating due to the possession of a combination of properties, such as good corrosion resistance, low density, and high ductility, etc. In previous researches, $\mathrm{Al}$ was co-deposited with $\mathrm{SiC}$ or $\mathrm{Al}_{2} \mathrm{O}_{3}$ particles to improve the stability of the ceramic coat on $\mathrm{Mg}$ alloy substrate (Ref 14-17). However, the Al layer in TBCs as bonding interlayer between TBCs (8YSZ top coat and MCrAlY bond coat) and $\mathrm{Mg}$ alloy substrate has not been investigated.

After deposition of $\mathrm{Al}$ coating on $\mathrm{Mg}$ alloy, there would be a diffused $\mathrm{Mg}$-Al layer on top of $\mathrm{Mg}$ alloy during heat treatment at certain temperature. The $\mathrm{Mg}$-Al diffused layer has high bond strength since there is a strong metallurgical bond between substrate and coat (Ref 18, 19). The alloyed layer mainly comprises intermetallic compounds. In Mg-Al binary alloy, the $\mathrm{Mg}-\mathrm{Al}$ intermetallic compound uniformly distributed in $\mathrm{Mg}$ matrix as the second phases which can improve the mechanical properties of the alloy. Mg-Al diffused coating was also prepared on top of $\mathrm{Mg}$ alloy to improve both the mechanical properties (Ref 20) and the corrosion resistance (Ref 21) of substrate. However, no investigation has been done to explore the thermalsprayed coats on $\mathrm{Mg}$ alloy with intermetallic compound interlayer.

After preparation of $\mathrm{Al}$ or diffused $\mathrm{Mg}-\mathrm{Al}$ layer on $\mathrm{Mg}$ alloy, the surface properties of substrate and structure of TBCs on $\mathrm{Mg}$ alloy were changed. The effect of the metallic interlayer on the bond stability of TBCs on $\mathrm{Mg}$ alloy should be investigated in order to obtain some useful information for preparation of TBCs on $\mathrm{Mg}$ alloy with long service life.

In the present work, $\mathrm{TBCs}$ with sprayed $\mathrm{Al}$ or diffused $\mathrm{Mg}$-Al interlayer on rare earth-magnesium alloy was investigated. Sprayed $\mathrm{Al}$ or diffused $\mathrm{Mg}$-Al layer was prepared on top of $\mathrm{Mg}$ alloy. In following, MCrAlY bond coat and 8YSZ top coat were deposited by APS. The preparation, microstructure, bond strength, and thermal shock resistance of the improved TBCs were studied in hope to find the optimized process of TBC formation on $\mathrm{Mg}$ alloys. The findings of this study are important for applications such as automotive, aerospace, medical implants, etc.

\section{Experimental}

Mg alloy MB26 (provided by Zhongke Ximei Magnesium Alloy Co., Changchun, China) was used as substrate material in this study (Ref 10).

Pure Al layer was deposited on top of Mg alloy substrate $(3 \mathrm{~mm} \times 20 \mathrm{~mm} \times 50 \mathrm{~mm})$ by arc spraying (AS) or atmospheric plasma spraying (APS). Prior to the deposition of $\mathrm{Al}$, the substrate was degreased with ethanol and grit blasted. AS pure $\mathrm{Al}$ wires was carried out with XDP-1 system under the following spraying conditions: voltage $30 \mathrm{~V}$, current $180 \mathrm{~A}$, atomizing air pressure $0.6 \mathrm{MPa}$, and spraying distance $100 \mathrm{~mm}$. Al powders were sprayed onto the pre-treated MB26 alloy substrates by APS with Unicoat Spraying System (F4 gun, Sulzer Metco, Switzerland) with $\mathrm{Ar}-\mathrm{H}_{2}$ as plasma gases. APS was carried out under the following spraying conditions: voltage $52.6 \mathrm{~V}$, current $600 \mathrm{~A}$, plasma gases $\left(\mathrm{Ar} / \mathrm{H}_{2}\right) 35 / 12$ standard liter per minute (SLPM), carrier gas (Ar) 2.6 SLPM, and the spraying distance was $100 \mathrm{~mm}$. The arc flame has a lower temperature and flight speed than plasma flame because the AS technique uses much lower current and gas pressure. The heat treatment of AS samples was carried out at $200{ }^{\circ} \mathrm{C}$ for $2 \mathrm{~h}$. The $\mathrm{Mg}$-Al diffused layer was prepared by annealing the sprayed (APS) sample with Al coat. The treatment was carried out at $400{ }^{\circ} \mathrm{C}$ for $10 \mathrm{~h}$. After heat treatment, the top oxidized layer was removed by gently grit blasting.

TBCs comprising MCrAlY bond coat and 8YSZ top coat were fabricated on the as-prepared interlayer or substrate by APS. Directly sprayed TBCs on Mg alloy substrate was prepared as contrast. Prior to the plasma spraying, the surface of $\mathrm{Mg}$ alloy substrate was degreased with ethanol and gently grit blasted with alumina sand (about $400 \mu \mathrm{m}$ ) in order to get a rough surface. Material for top coat was 8YSZ (204NS, Sulzer Metco, Switzerland) powder. The powder of bond coat was NiCoCrAlY purchased from Beijing General Research Institute of Mining and Metallurgy. The powders were spheroidized with the particle size about $45-105 \mu \mathrm{m}$. Bond coat and top coat have thicknesses of about 150 and $300 \mu \mathrm{m}$, respectively.

The dilatometric measurement of MB26 alloy, Al, $\mathrm{Mg}-\mathrm{Al}$ diffused intermetallic compound, NiCoCrAlY bond coat and 8YSZ were carried out with a high temperature dilatometer (Netzsch 402C). During the dilatometric measurement, a small piece of sample with dimensions of $1.3 \mathrm{~mm} \times 5 \mathrm{~mm} \times 25 \mathrm{~mm}$ was heated from 50 to $4500^{\circ} \mathrm{C}$ with a heating rate of $5^{\circ} \mathrm{C} / \mathrm{min}$ and then held for $10 \mathrm{~h}$ followed by cooling down to room temperature.

The roughness of the substrate surface after the failure of the coats was measured by a handheld roughness tester (TR200, Times Co., Beijing, China).

Small discs with diameter of $12 \mathrm{~mm}$ were coated for tensile bond strength measurement. The bond strength tests were carried out using an Instron (1121 USA) machine with a tensile speed $2 \mathrm{~mm} / \mathrm{min}$ based on ISO 4624. The final value was obtained after averaging at least three measurements. 
The thermal shock test was performed to determine the life time of the coats when subjected to a rapid temperature change. The steps in the thermal shock process are following: the coated sample was constantly heated for 15 min at 400 or $300{ }^{\circ} \mathrm{C}$ in a furnace followed by sudden quenching into coolant, the sample was dried by air flow and then re-heated in the furnace. This procedure was repeated until the failure in form of whole coating delamination and the thermal cycling number was the life time of the coating. The final value was obtained after averaging at least two measurements.

Microhardness test was carried out on a polished cross section of coated sample by Vicker's hardness tester (FM-700, Future-Tech, Japan) with a load of $150 \mathrm{~g}$ for $15 \mathrm{~s}$, and 10 measurements were averaged for each specimen.

The thermal and oxidation properties of the substrate and the diffused intermetallic compound under high temperature up to $600{ }^{\circ} \mathrm{C}$ were investigated by using thermogravimetry and differential scanning calorimetry (TG-DSC, STA 449F3, Netzsch) with a heating rate of $10 \%$ min in air atmosphere.

The corrosion of substrate and the $\mathrm{Mg}$ - $\mathrm{Al}$ diffused layer was evaluated by electrochemical corrosion test. 3.5 wt. \% $\mathrm{NaCl}$ solution was used as corrosion medium. Electrochemical corrosion of $\mathrm{Mg}$ alloy substrate and the $\mathrm{Mg}$-Al diffused layer was evaluated by potentiodynamic polarization. An electrochemical workstation (CHI 660A, $\mathrm{CH}$ Instruments) together with a conventional threeelectrode cell was used to perform polarization curves of the samples in $3.5 \% \mathrm{NaCl}$ solutions at room temperature. A platinum counter electrode and a glassy carbon reference electrode (GCE) were used. The polarization curves were scanned from a cathodic potential of $-1.8 \mathrm{~V}$ to an anodic potential of $0 \mathrm{~V}$ at a rate of $0.01 \mathrm{~V} / \mathrm{s}$.

The surface and cross section of the samples were studied by scanning electron microscopy (SEM, XL-30ESEM FEG, Mico FEI Philips) equipped with energy dispersive $\mathrm{x}$-ray spectrometer (EDS). In order to study the cross-sectional morphologies, the samples were solidified by resin and polished with diamond polishing slurries up to $1 \mu \mathrm{m}$. The crystal structures of the samples were analyzed by x-ray diffraction (XRD) (Bruker D8
Advance Diffractometer with $\mathrm{Cu} \mathrm{K} \alpha$ radiation, $\lambda=0.15406 \mathrm{~nm}$ ).

\section{Results and Discussion}

\subsection{Preparation of Al Coat or Diffused Mg-Al Diffused Layer on Mg Alloy}

Al coats were prepared on MB26 alloy substrate by AS and APS, respectively. The cross-sectional morphologies of the samples with $\mathrm{Al}$ coat were shown in Fig. 1. As shown in Fig. 1(a), there are many microcracks in AS Al coat. Most of microcracks are laterally distributed, paralleling to the bond interface. The $\mathrm{Al}$ coat compactly bonds with $\mathrm{Mg}$ alloy substrate. Crack or pore hardly emerges at the interface between coat and substrate. The $\mathrm{Mg}$ alloy substrate is intact. The arc heat flux has no obviously impact on $\mathrm{Mg}$ alloy substrate.

For the APS Al coat as shown in Fig. 1(b), there is almost no microcrack, only a few micropores appeared. The APS Al coat also compactly bonds with $\mathrm{Mg}$ alloy substrate. Besides, a diffused layer (about $5 \mu \mathrm{m}$ ) was formed at the bond interface. The diffused layer mainly comprises $\mathrm{Mg}$ and $\mathrm{Al}$. It is possible that the top of substrate re-melted under the plasma flame. With the diffusion between the $\mathrm{Al}$ coat and the heated $\mathrm{Mg}$ alloy substrate, a thin $\mathrm{Mg}-\mathrm{Al}$ intermetallic layer might be formed.

With regard to the thermal-sprayed $\mathrm{Al}$ coat which prepared by different techniques under the optimum parameters, the microstructure and the bond interface are mainly affected by the temperature and flight speed of the flame. Plasma flame has higher temperature and flight speed than arc flame. During APS, Al particles almost completely melted in plasma flame and in the moment when the particles spread on substrate surface. The following Al phase integrated with the previous spread and melted Al layer. The micropores formed mainly due to the gas cavity in the $\mathrm{Al}$ coat. With the melted Al spreading and solidifying on $\mathrm{Mg}$ alloy substrate, there is diffusion between substrate and coat. The APS Al coat bonds with substrate mainly by metallic bond.
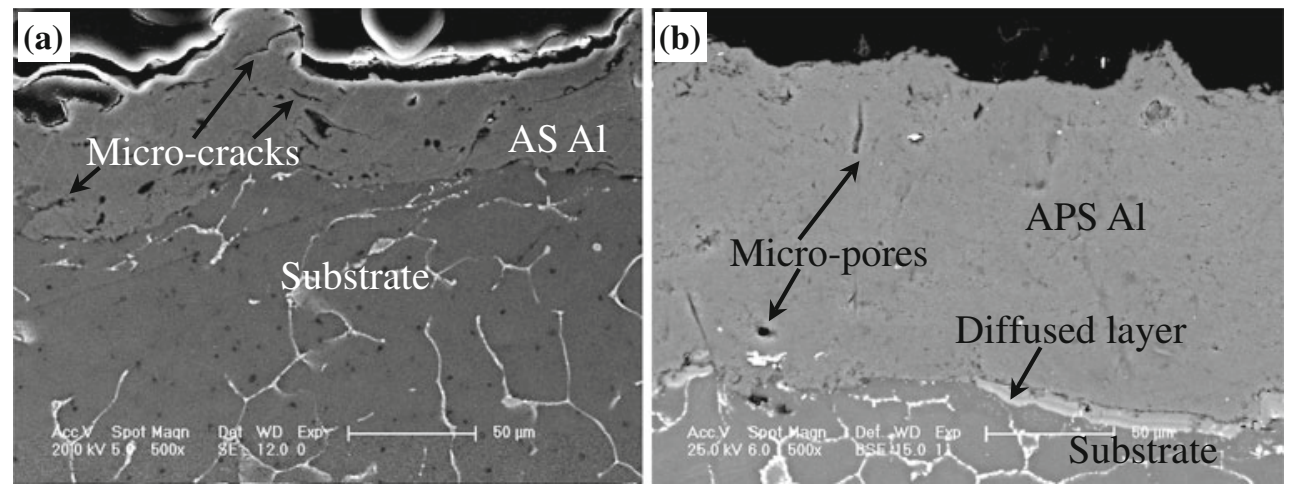

Fig. 1 Cross-sectional morphologies of the as-sprayed Al layer on MB26 alloy. (a) AS sprayed sample, (b) APS sprayed sample 
While AS shows a different deposition process; compared with plasma flame, arc flame has low temperature. The melted $\mathrm{Al}$ particles have low temperature. After the Al particles impacting and spreading on substrate, they quickly solidified forming a small flake. As the flakes accumulating, a thick coat showing typical laminar structure was deposited. The substrate has low temperature during AS. Through the EDS surface scanning analysis as shown in Fig. 2(a), $\left(\mathrm{a}^{\prime}\right)$, and $\left(\mathrm{a}^{\prime \prime}\right)$, no diffusion was occurred between $\mathrm{Al}$ coat and substrate. In order to improve the bond strength between the coat and substrate, heat treatment (annealing) at $200{ }^{\circ} \mathrm{C}$ for $2 \mathrm{~h}$ was adopted. After the treatment, the morphologies of the coated sample do not change (Fig. 2b). Obviously, diffusion took place between $\mathrm{Al}$ coat and substrate (Fig. $2 \mathrm{~b}^{\prime}, \mathrm{b}^{\prime \prime}$ ). There is metallurgical bond between coat and substrate which could improves the bond strength of $\mathrm{Al}$ coat. In thermal shock test (from $400{ }^{\circ} \mathrm{C}$, into cold water), it is confirmed that the thermal shock resistance of the sprayed sample is improved from 40 to 50 cycles after annealing.

Diffused $\mathrm{Mg}$ - $\mathrm{Al}$ layer was prepared on top of $\mathrm{Mg}$ alloy substrate by annealing the APS sample (with Al coat) at $400{ }^{\circ} \mathrm{C}$ for $10 \mathrm{~h}$. Fig. 3(a) shows the cross-sectional morphology of the sample after annealing. A distinct alloyed layer was observed on top of MB26 alloy substrate. It is also found that the alloyed layer has two regions. The top layer is porous. It is mainly due to the oxidation of the diffused layer surface during heating. In order to obtain pure and dense diffused layer, the oxidized layer was removed by gently blasting in the following process. Under the porous top layer, there is a continuous and integral phase with a thickness about $80 \mu \mathrm{m}$. The EDS
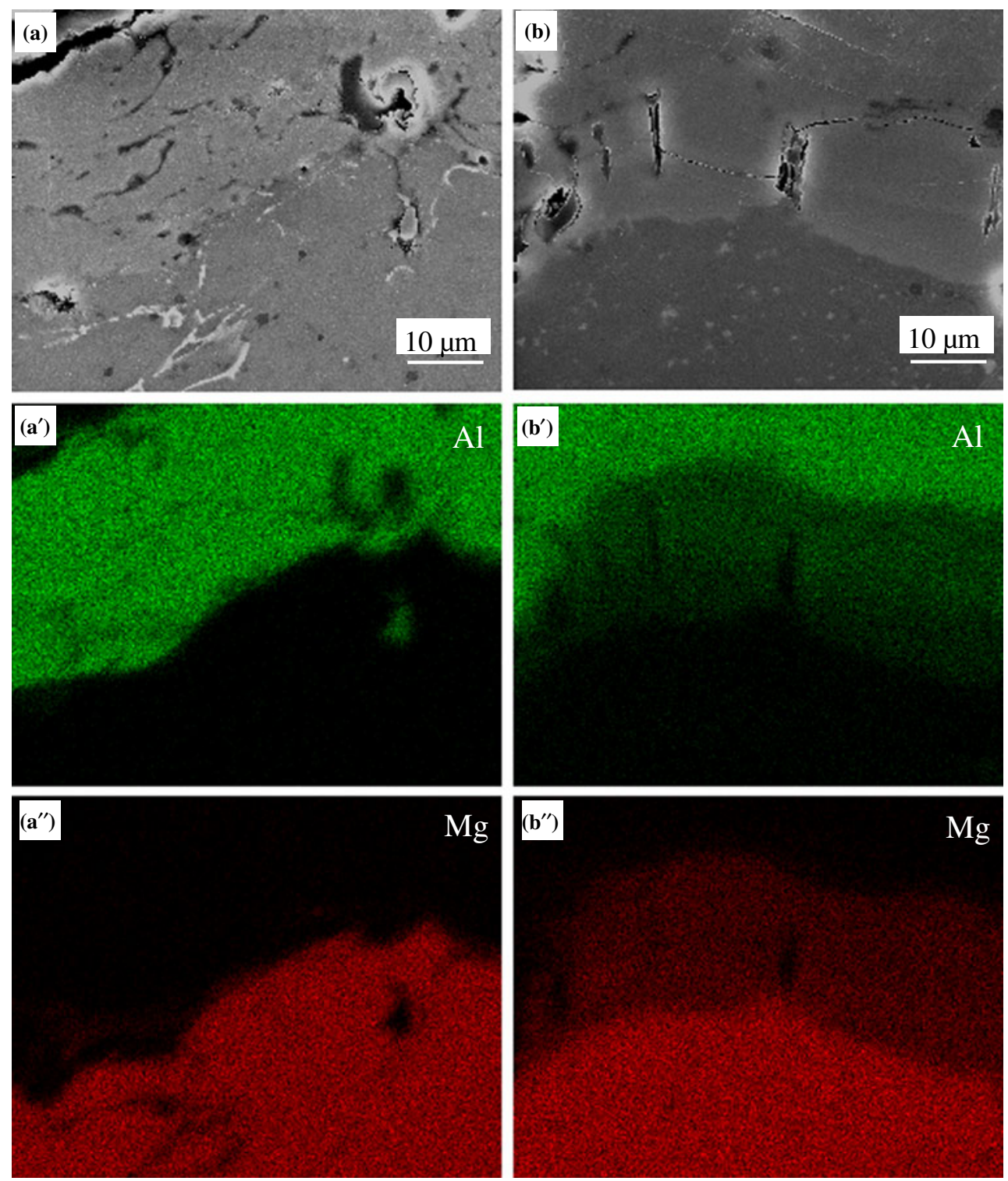

Fig. 2 SEM micrograph of MB26/Al cross section (a) and the corresponding elemental analyses by EDS (a ${ }^{\prime}$, $\left.a^{\prime \prime}\right)$; SEM micrograph of $\mathrm{MB} 26 / \mathrm{Al}$ cross section after $200{ }^{\circ} \mathrm{C}$ heat treatment (b) and the corresponding elemental analyses by EDS $\left(\mathrm{b}^{\prime}, \mathrm{b}^{\prime \prime}\right)$ 
analysis shows that this layer is mainly composed of $\mathrm{Mg}$ and Al (Fig. 3b-d). The quantitative analysis of the chemical composition was obtained by EDS corresponding to the marked points in Fig. 3(a). The Mg concentration is 52.06 at. \% and the $\mathrm{Al}$ concentration is 47.94 at.\%. The Mg-Al binary phase diagram has both terminal and intermediate phases (Ref 22). Intermediate solid-solution phases in a certain composition range are separated from other phases in a binary diagram by two-phase regions. The phase $\mathrm{Al}_{12} \mathrm{Mg}_{17}$ has a wide composition range with $\mathrm{Al}$ concentration from 37.7 to 56.8 at.\% (Ref 18). It is possible that the diffusion layer mainly comprises of $\mathrm{Al}_{12} \mathrm{Mg}_{17}$ phase.

To further understand the atom diffusion process and the elements distribution in the alloyed layer, SEM with EDS linear scan analysis was carried out to investigate the composition variation from the alloyed layer to the substrate. Figure 4 shows that the contents of $\mathrm{Mg}$ and $\mathrm{Al}$ mainly remain at a constant value from the top of alloyed layer to the boundary between the diffused layer and substrate. It could be concluded that the alloyed layer has uniform composition.

After preparing $\mathrm{Al}$ coat or $\mathrm{Mg}-\mathrm{Al}$ diffused layer on MB26 alloy substrate, the coat was examined by XRD. The results are shown in Fig. 5. The diffraction peaks of the sprayed (APS and AS) coat are assigned to pure Al, which is well consistent with the standard card JCPDS 65-2869. It also confirms that no oxidation reaction occurs in the $\mathrm{Al}$ coat during thermal spray. The XRD patterns of diffused $\mathrm{Mg}$-Al layer are consistently indexed assuming a bcc structure for $\mathrm{Al}_{12} \mathrm{Mg}_{17}(a=10.560 \mathrm{~nm}, b=10.560 \mathrm{~nm}$, $c=10.560 \mathrm{~nm})$ and a fcc structure for $\mathrm{Al}_{3} \mathrm{Mg}_{2} \quad(a=$ $28.239 \mathrm{~nm}, b=28.239 \mathrm{~nm}, c=28.239 \mathrm{~nm}$ ) (Ref 23). The identified phases are consistent with the $\mathrm{Mg}$ - $\mathrm{Al}$ binary phase diagram. Taking into account the EDS analysis results, it is confirmed that the diffused $\mathrm{Mg}$ - $\mathrm{Al}$ layer is mainly composed of $\mathrm{Al}_{12} \mathrm{Mg}_{17}$. A little $\mathrm{Al}_{3} \mathrm{Mg}_{2}$ is coexisted. As shown in Fig. 5, the diffraction pattern of $\mathrm{Al}_{17} \mathrm{Mg}_{12}$ shows stronger peaks than that of $\mathrm{Al}_{3} \mathrm{Mg}_{2}$.

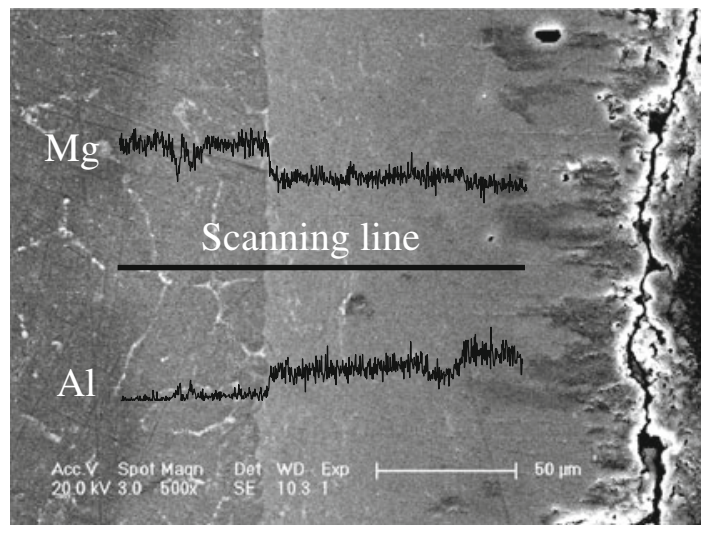

Fig. 4 Cross section elemental analysis of $\mathrm{Mg}$-Al diffused layer by EDS linear scanning
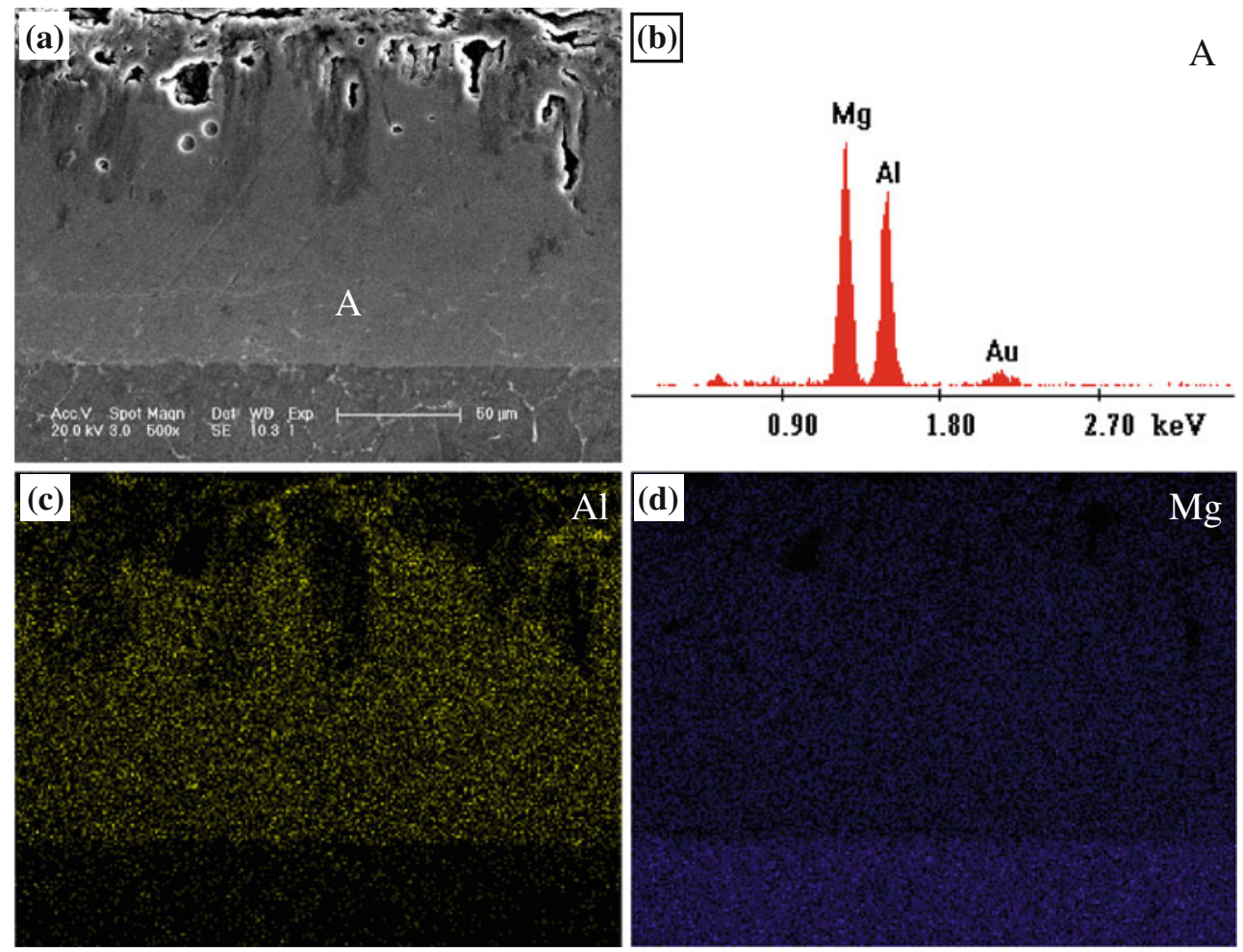

Fig. 3 (a) cross-sectional morphology of APS Al coat on MB26 alloy after heat treatment at $400{ }^{\circ} \mathrm{C}$ for 10 h; (b) EDS spectra of corresponding locations " $A$ " in (a); (c, d) elemental analyses of (a) by EDS surface scanning 


\subsection{Preparation of TBCs on Mg Alloy with Interlayer}

After preparation of $\mathrm{Al}$ coat or $\mathrm{Mg}-\mathrm{Al}$ diffused layer, the TBCs which is composed of MCrAlY bond coat and 8 YSZ top coat was deposited. In order to investigate the effect of interlayer on the performance of TBCs, the TBCs on MB26 substrate without interlayer was also presented.

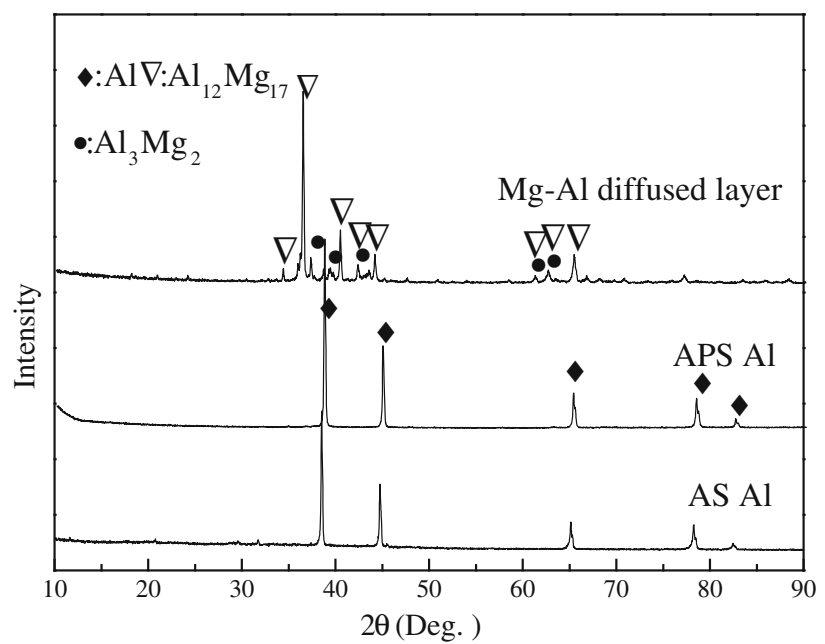

Fig. 5 XRD patterns of the samples after preparing Al coat and $\mathrm{Mg}-\mathrm{Al}$ diffused layer on MB26 alloy
The cross-sectional morphologies of the as-prepared TBCs were shown in Fig. 6. As discussed in our previous work (Ref 10$)$, when directly sprayed TBCs on Mg alloy by APS, the substrate was affected by the plasma flame. A HAL was formed on substrate. There are re-melting and oxidation in HAL (Fig. 6a). For the samples with $\mathrm{Al}$ interlayer, the APS TBCs is compactly bonded with Al layer. No HAL emerged on $\mathrm{Mg}$ alloy substrate. The plasma flame has no obvious effect on Al layer. The microstructure of the sprayed Al coat does not change. There are also some microcracks in AS Al layer (Fig. 6b), and some micropores in APS Al layer (Fig. 6c). However, for the sample with $\mathrm{Mg}$-Al diffused interlayer, the plasma flame seriously affected the diffused layer. A thick HAL about $30 \mu \mathrm{m}$ emerged (Fig. 6d). There are a lot of mechanical occlusion between bond coat and diffused layer. The whole TBCs compactly bonds with $\mathrm{Mg}$ alloy substrate. The substrate surface which adheres to the sprayed TBCs affects the bond properties of the coat. The melting point of $\mathrm{Al}\left(660^{\circ} \mathrm{C}\right)$ is higher than $\mathrm{Mg}\left(650^{\circ} \mathrm{C}\right)$. Under oxidizing condition, a dense oxide film would grow on $\mathrm{Al}$ surface to improve the thermal resistance and oxidation resistance of $\mathrm{Al}$ layer. The $\mathrm{Al}$ coat could withstand the impact of the plasma flame and shield the $\mathrm{Mg}$ alloy substrate from the heat affect. Therefore, no re-melting and oxidation could be observed in $\mathrm{Al}$ coat. No HAL emerges on $\mathrm{Mg}$ alloy substrate.

Compared with the directly sprayed sample (MB26/ $\mathrm{BC} / 8 \mathrm{YSZ}$ ), the sample with $\mathrm{Mg}$-Al diffused interlayer is even more severely affected by the plasma flame. The
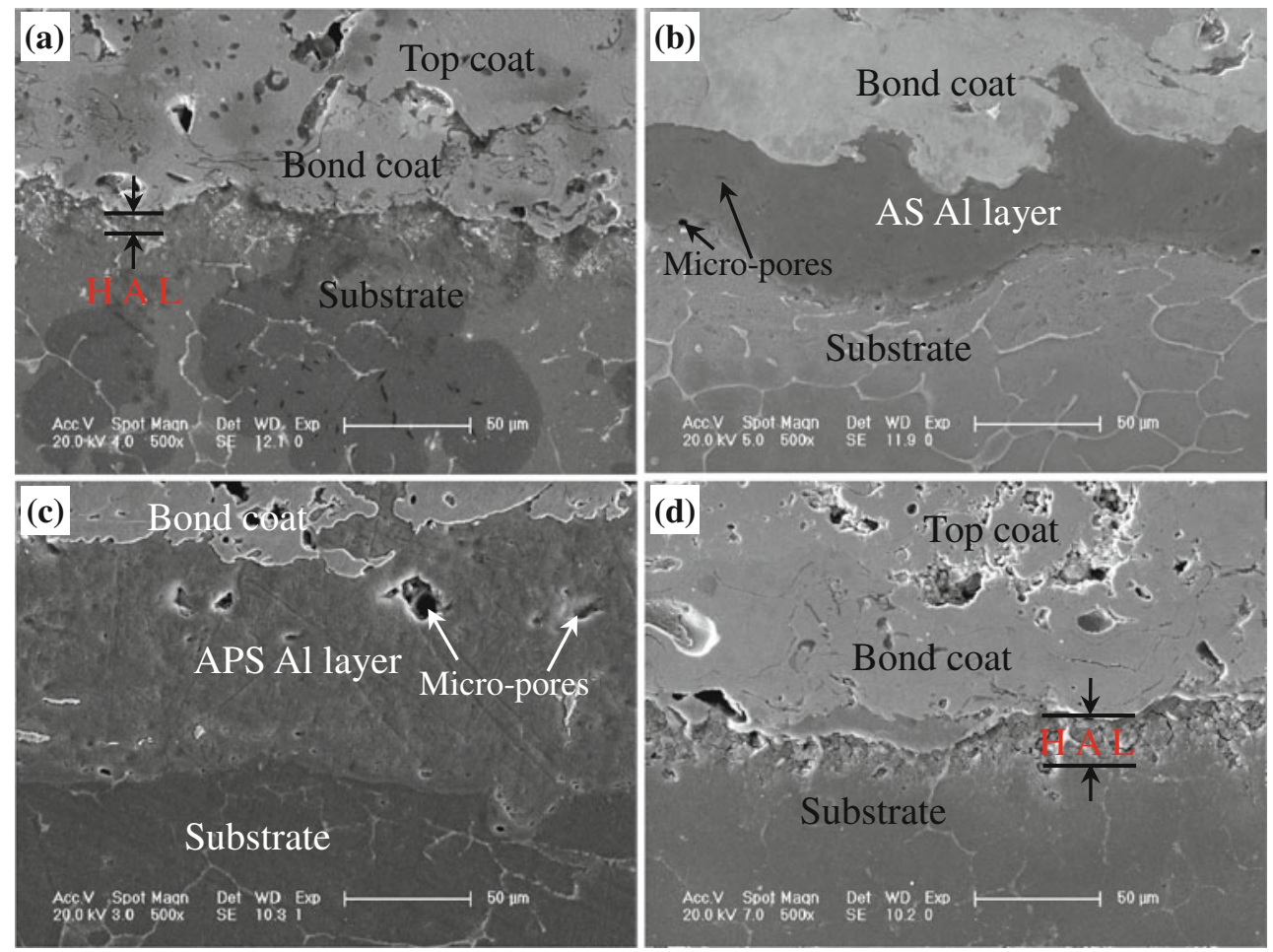

Fig. 6 Cross-sectional morphologies of TBCs on MB26 alloy substrate. (a) MB26/BC/8YSZ, (b) MB26/Al(AS)/BC/8YSZ, (c) MB26/ Al(APS)/BC/8YSZ, (d) MB26/Mg-Al(diffused)/BC/8YSZ 

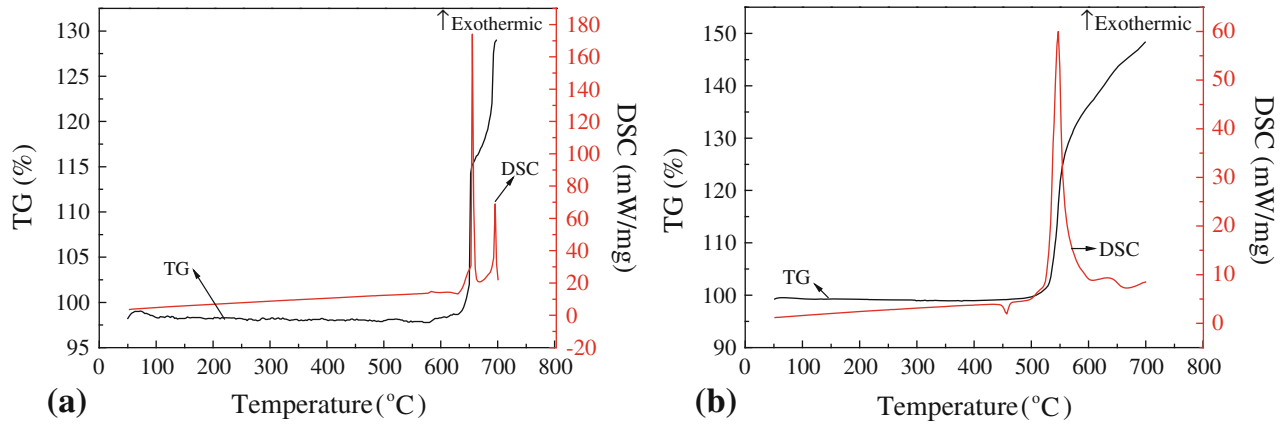

Fig. 7 TG-DSC spectrums of the samples in air atmosphere. (a) MB26 substrate, (b) Mg-Al diffused layer

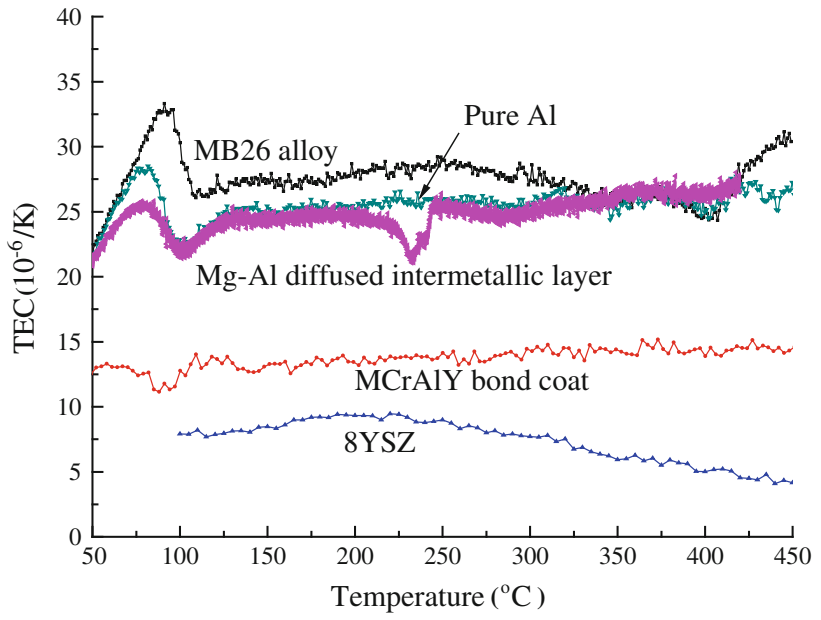

Fig. 8 Comparison of thermal expansion coefficients (TECs) of $\mathrm{MB} 26$ alloy, bond coat, $\mathrm{Mg}-\mathrm{Al}$ diffused layer, $\mathrm{Al}$ and $8 \mathrm{YSZ}$ in the temperature range of $50-450{ }^{\circ} \mathrm{C}$

behaviors of MB26 alloy and Mg-Al diffused layer at high temperature were investigated by TG-DSC in $\mathrm{N}_{2} / \mathrm{O}_{2}$ atmosphere. The results of TG-DSC were shown in Fig. 7. The DSC and TG spectrums of MB26 alloy show subtle change in the equilibrium stage of the test $\left(50-650{ }^{\circ} \mathrm{C}\right)$, almost maintaining level as shown in Fig. 7(a). The results indicate that no reaction occurs, MB26 alloy almost keeps stable below $650{ }^{\circ} \mathrm{C}$. At 650 and $700{ }^{\circ} \mathrm{C}$, two strong exothermic peaks emerged in the DSC curve of MB26 alloy. The exothermic peak mainly involves the reaction between $\mathrm{Mg}$ alloy and the atmosphere $\left(\mathrm{O}_{2}\right.$ and $\left.\mathrm{N}_{2}\right)$. In the whole DSC spectrum, no endothermic peak emerges. It is possible that the large heat released from the oxidation leads to the melting of MB26 alloy. It is concluded that the melting and oxidation of MB26 alloy might occur simultaneously. In addition, the TG curve of MB26 sharply increases above $650{ }^{\circ} \mathrm{C}$. It confirms that obvious oxidation of MB26 alloy in dry air atmosphere occurs above $650{ }^{\circ} \mathrm{C}$. In Fig. 7(b), the DSC and TG spectrums of Mg-Al diffused layer show subtle change at low temperature region (50-450 $\left.{ }^{\circ} \mathrm{C}\right)$. An endothermic peak in the DSC spectrum emerges at $450{ }^{\circ} \mathrm{C}$. The endothermic peak relates with the melting of $\mathrm{Mg}-\mathrm{Al}$ diffused layer. The results are fully consistent with the $\mathrm{Al}_{12} \mathrm{Mg}_{17}$ and $\mathrm{Al}_{3} \mathrm{Mg}_{2}$ phases of the

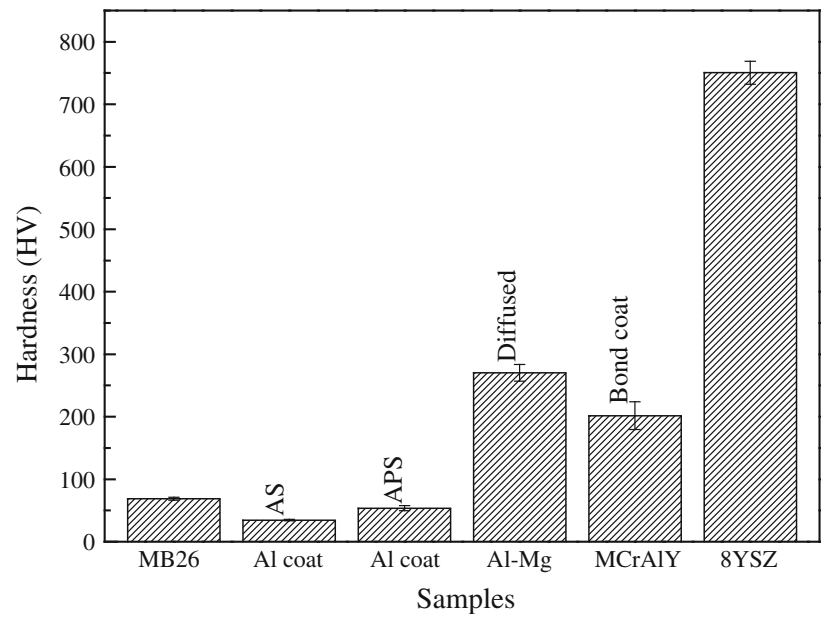

Fig. 9 Hardness of coats and substrate

Mg-Al binary phase diagram. For the TG-DSC spectrums of $\mathrm{Mg}$-Al diffused layer at $550{ }^{\circ} \mathrm{C}$, a high exothermic peak emerges, and the TG curve sharply increases. The results indicate that obvious oxidation of $\mathrm{Mg}$ - $\mathrm{Al}$ diffused layer in dry air atmosphere occurs above $550{ }^{\circ} \mathrm{C}$. In the heat process, the melting of $\mathrm{Mg}-\mathrm{Al}$ diffused layer precedes the oxidation of the layer. On the basis of the TG-DSC spectrums analysis, it can be noted that MB26 alloy has higher melting point than $\mathrm{Mg}$-Al diffused layer. Therefore, thicker HAL emerged in $\mathrm{Mg}$-Al diffused layer than in MB26 alloy substrate (Fig. 6a, d). It is interestingly found that the melting of $\mathrm{Mg}$-Al diffused layer precedes the oxidation of the layer, and the melting and oxidation of MB26 alloy might occur simultaneously. Mg-Al diffused layer is prone to melt without severe oxidation at $450-550{ }^{\circ} \mathrm{C}$. During plasma spraying, although the surface has high instantaneous temperature when the droplets impact on substrate, the overall temperature of substrate is lower than $500{ }^{\circ} \mathrm{C}$. Thus, $\mathrm{Mg}$ - $\mathrm{Al}$ diffused layer could well melt to increase the interlock between TBCs and substrate without severe oxidation.

The physical properties of coat and substrate affect the bond stability of the TBCs. The physical properties (such as TEC, hardness) of the coats and substrate were evaluated by dilatometric measurement and hardness test. 
The TECs of substrate and each part of coat are shown in Fig. 8. TEC of MB26 is $26 \times 10^{-6} \mathrm{~K}^{-1}$. TECs of $8 \mathrm{YSZ}$ top coat and MCrAlY bond coat are $8 \times 10^{-6}$ and $13 \times 10^{-6} \mathrm{~K}^{-1}$, respectively. There is large mismatch of TEC between 8YSZ and MB26 alloy substrate. After deposition of MCrAlY bond coat, the TEC difference between top coat and substrate is reduced. There is also large TEC difference between bond coat and substrate. TECs of $\mathrm{Al}$ coat and $\mathrm{Mg}$-Al diffused layer are $25 \times 10^{-6}$ and $24 \times 10^{-6} \mathrm{~K}^{-1}$, respectively. If an $\mathrm{Al}$ or $\mathrm{Mg}$ - $\mathrm{Al}$ diffused layer was pre-prepared on $\mathrm{Mg}$ alloy substrate before the deposition of TBCs, the TEC difference between bond coat and substrate could be further reduced.

The hardness tests of the coatings were made on the polished cross sections. The hardness values of coats and substrate are presented in Fig. 9. After spraying Al coat, the hardness of MB26 substrate (about $68.8 \mathrm{HV}$ ) is reduced. The AS Al coat and APS Al coat have low hardness about 34.5 and $53.7 \mathrm{HV}$, respectively. It is mainly due to the characteristics of the sprayed Al coat. Not only pure $\mathrm{Al}$ has low hardness, but also plenty of microcracks and micropores distribute in sprayed coat. However, after preparation of $\mathrm{Mg}-\mathrm{Al}$ diffused layer on MB26 alloy, the hardness of substrate is significantly increased to $270 \mathrm{HV}$, which is similar to the hardness value of the bond coat. The high hardness of substrate would expect to obtain good mechanical properties.

\subsection{Bond Properties of TBCs on Mg Alloy with Interlayer}

3.3.1 Tensile Bond Strength. The bond strengths of the $\mathrm{TBC}$ on $\mathrm{Mg}$ alloy substrate with different structure were evaluated by tensile test. The results are shown in Fig. 10. The bond strength of the directly sprayed TBCs is 7.6 $\mathrm{MPa}$. Compared with the directly sprayed sample, the bond strength of the TBCs with APS Al or Mg-Al diffused layer is increased. However, the bond strength of the TBCs with AS Al interlayer is reduced.

The structure and the mechanical properties of the interlayer have an important influence on the bond strength of the TBCs. In order to explore the relationship between them, the failure of these four samples were investigated in detail. The cross-sectional and the substrate surface morphologies after the failure are shown in Fig. 11. The failure of the directly sprayed TBCs occurred at the interface between substrate and bond coat (Fig. 11a). After the failure of TBCs, there are many crates and tiny oxides on the substrate surface (Fig. 11a'). As discussed above, oxidation occurred along with the melting of $\mathrm{Mg}$ alloy. When directly sprayed TBCs on $\mathrm{Mg}$ alloy, the substrate surface was oxidized as the substrate melting. The bond coat interlocked with substrate in HAL, and oxides emerged at the interface. In tensile test, the pulling force was vertically loaded on the coats. The interlocked interface provided limited resistance for the deformation in vertical direction. The fragile oxides were crushed leading to the dissociation of the mechanical occlusion. Finally, the coat was detached from substrate. Therefore, as shown in Fig. 11(a) and $\left(a^{\prime}\right)$, the failure of the directly sprayed TBCs occurs at the interface between substrate and bond coat.

The failure of the TBCs with AS Al interlayer occurs in $\mathrm{Al}$ layer or at the interface between Al layer and substrate during tensile test (Fig. 11b). On the substrate surface of the failed sample, some small Al flakes remain (Fig. 11b'). AS has low temperature and flight speed to fully melt and compact the $\mathrm{Al}$ flakes. The occlusion between $\mathrm{Al}$ layer and substrate is not sufficient. There are microcracks in the Al layer and at the bond interface. Al layer do not fully contact with substrate. Although diffusion occurred during heat treatment in the location where the Al layer was compactly bonded with substrate, the microcracks also existed. Such structure made AS Al layer have low strength. Besides, it made the Al layer have low bond strength with $\mathrm{Mg}$ alloy substrate. While the APS bond coat is entirely combined with Al layer due to the high temperature and flight speed of APS flame. Under the vertical tensile stress, the microcracks propagated resulting in the coats flaking. Therefore, the failure of the TBCs with AS Al interlayer occurs in $\mathrm{Al}$ layer or at the interface between $\mathrm{Al}$ layer and substrate. Accordingly, the bond strength of the TBCs on Mg alloy with AS Al interlayer is low.

APS flame has high temperature and flight speed. The Al flake on Mg alloy could be well melted and compacted. Compared with AS Al layer, APS Al layer has high density. Only a few micropores emerge in Al layer. In addition, with the presence of diffused layer (Fig. 1b), the bond strength of APS Al layer is further increased through metallic bond. On the basis of the fine structure, the APS Al would have high strength, and the bond strength between APS Al and Mg alloy substrate would be high. After the deposition of bond coat on Al layer by APS, the bond coat compactly bonds with Al layer similar with the bond condition between bond coat and AS Al layer. In tensile test, stress concentration firstly took place in the defects of Al layer. Once the Al layer could not suffer the tensile stress, cracks would emerge in the defects, and then the whole coat peeled off. As shown in Fig. 11(c), the failure of the TBCs with APS Al interlayer mainly occurs

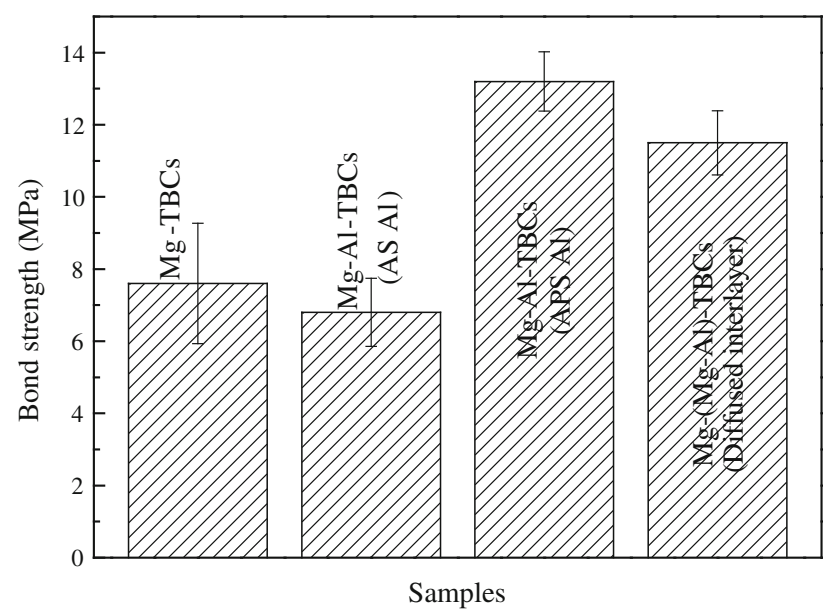

Fig. 10 Tensile bond strengths of TBCs on MB26 alloy substrate with different structure

(n) 

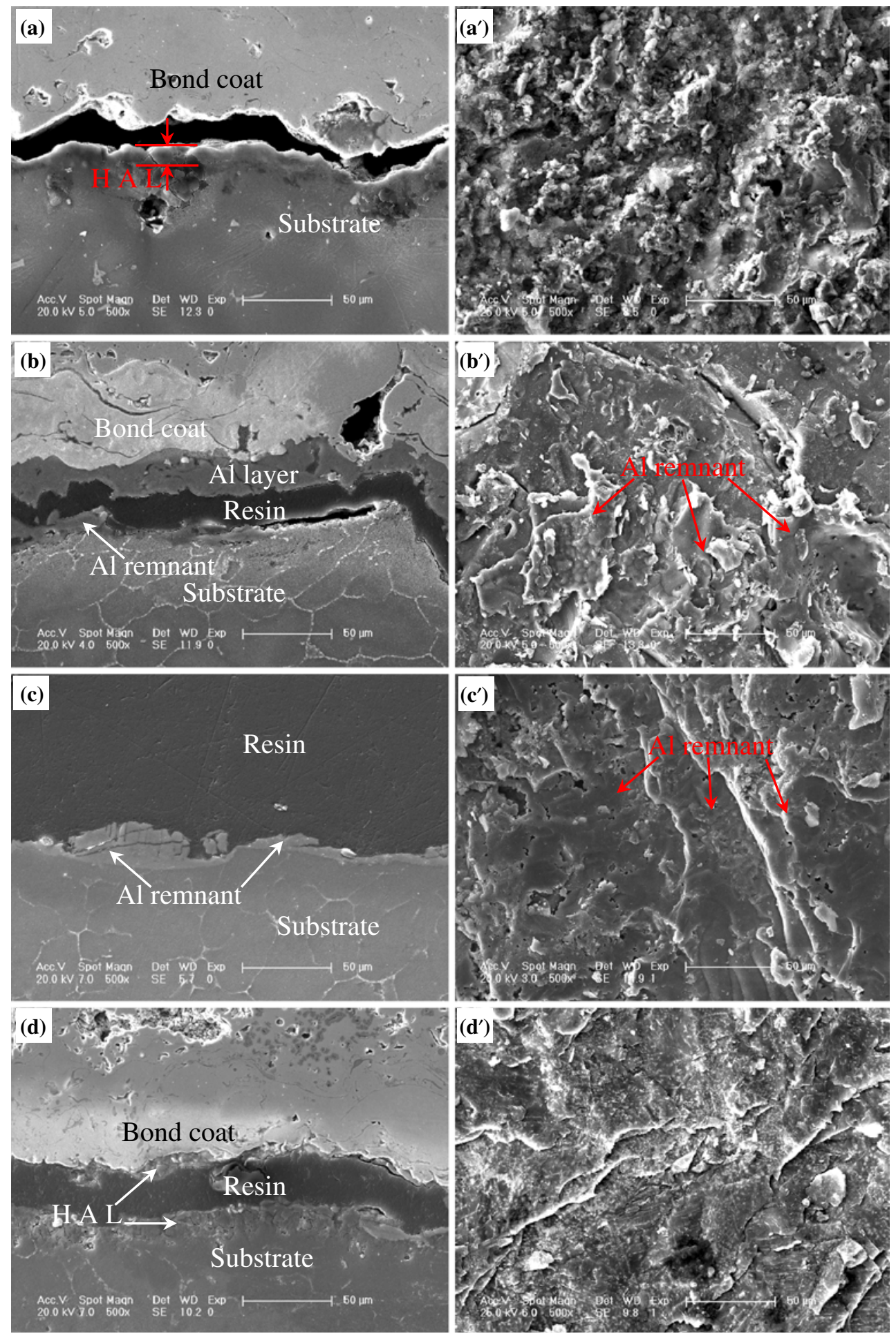

Fig. 11 SEM images of failed samples in tensile test. Cross-sectional morphologies of (a) MB26/BC/8YSZ, (b) MB26/Al(AS)/BC/8YSZ, (c) MB26/Al(APS)/BC/8YSZ, (d) MB26/Mg-Al(diffused)/BC/8YSZ. (a'-d') The corresponding morphologies of substrate surface

in $\mathrm{Al}$ layer. A thin $\mathrm{Al}$ layer is remained on substrate. There are many microcracks distributed in the remaining Al layer (Fig. 11c). It reveals the propagation of the cracks. On the substrate surface of the failed sample, the remaining $\mathrm{Al}$ is compactly coated on the substrate surface.
The grains of the $\mathrm{Al}$ flakes are distributed in the same direction (Fig. 11c'). It indicates the failure originates from the defects in $\mathrm{Al}$ coat.

As shown in Fig. 11(d), the failure of the TBCs on $\mathrm{Mg}$ alloy substrate with $\mathrm{Mg}$ - $\mathrm{Al}$ diffused interlayer occurs in 
the $\mathrm{Mg}-\mathrm{Al}$ diffused layer. The sample structure affects the bond strength of TBCs. During APS, the substrate was heated by the plasma flame and the heat which is transformed from the kinetic energy of the particles. $\mathrm{Mg}-\mathrm{Al}$ diffused layer has low melting point. $\mathrm{Mg}-\mathrm{Al}$ diffused layer could be melted without oxidation at $450-550{ }^{\circ} \mathrm{C}$ (Fig. $7 \mathrm{~b}$ ). Before the particles impacting on substrate, the substrate was partly melted without obvious oxidation in preheating process. At first, the particles could insert into the melted layer without the interface oxidation. As more particles impinging on the diffused layer surface, the instantaneous temperature of substrate surface increased to more than $550{ }^{\circ} \mathrm{C}$. The diffused layer was further melted. Meanwhile, obvious oxidation took place at diffused layer surface. The following particles could well insert into the melted layer. However, there is obvious oxidation at the bond interface. Overall, the APS bond coat is well interlocked with $\mathrm{Mg}-\mathrm{Al}$ diffused layer, the interface is partly oxidized. $\mathrm{Mg}$-Al diffused layer has high hardness (about $270 \mathrm{HV}$ ). It can bear high compressive stress in the plastic deformation range. However, the intermetallic compound has high intergranular embrittlement. The deformation resistance of $\mathrm{Mg}$-Al diffused layer is poor. In tensile test, there would be longitudinal deformation in $\mathrm{Mg}$ - $\mathrm{Al}$ diffused layer under the vertical tensile load. The stress concentration emerged at the peak of the inserted bond coat. The crack could horizontally extend in $\mathrm{Mg}-\mathrm{Al}$ diffused layer. Therefore, it is observed that the failure of this sample occurs in the $\mathrm{Mg}$-Al diffused interlayer, and the fracture surface is level with the flat of the inserted bond coat peak (Fig. 11d). As shown in Fig. 11( $\left.\mathrm{d}^{\prime}\right)$, the squamous residues in substrate surface reveal the propagation process of the cracks. Although APS bond coat bonded well with Mg-Al diffused layer, the intergranular embrittlement of diffused layer made the bond strength of the TBCs reduce.

3.3.2 Thermal Shock Resistance. The thermal shock resistance of the coated samples was evaluated by quenching the heated sample into cold coolant $\left(25^{\circ} \mathrm{C}\right)$. Water and anhydrous ethanol were used as the coolant.

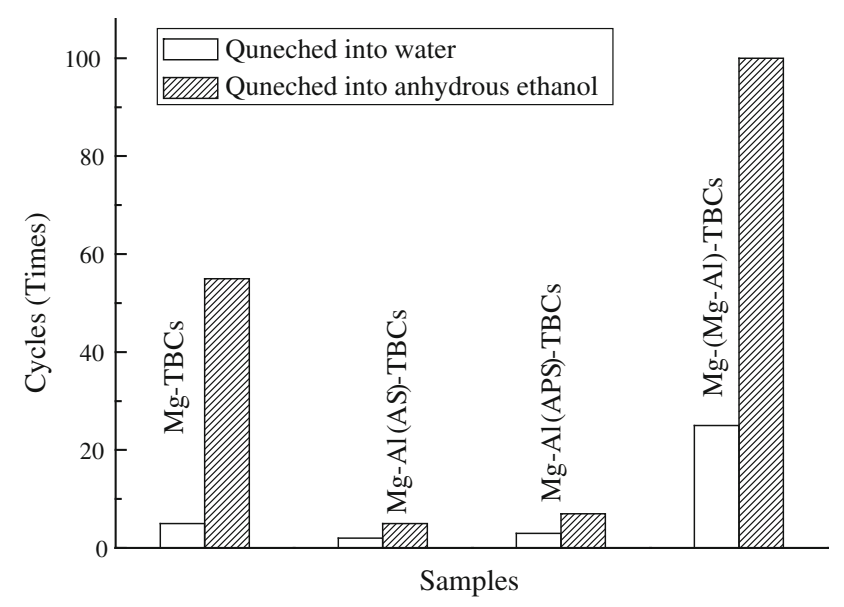

Fig. 12 Thermal shock test results of the samples after quenching from $400{ }^{\circ} \mathrm{C}$ to room temperature
The thermal shock cycles of the samples for quenching from $400{ }^{\circ} \mathrm{C}$ are shown in Fig. 12 . The directly sprayed sample has short cycle life (about 5 cycles) when it is quenched from $400{ }^{\circ} \mathrm{C}$ into cold water. After pre-depositing $\mathrm{Mg}$-Al diffused layer, the thermal shock cycles of the TBCs on $\mathrm{Mg}$ alloy is improved (about 25 cycles). When the directly sprayed sample and the sample with $\mathrm{Mg}-\mathrm{Al}$ diffused interlayer are quenched from $400{ }^{\circ} \mathrm{C}$ into anhydrous ethanol, the thermal shock cycles of them is increased to 55 and 100 cycles, respectively. However, whether quenched into water or anhydrous ethanol, the samples with AS Al or AS Al interlayer have shorter cycle life compared with the directly sprayed sample.

The failure location of the samples with AS Al or AS Al interlayer in thermal shock test is similar with the failure location of them in tensile test. In thermal shock test, the failure of the coated samples with sprayed $\mathrm{Al}$ interlayer is mainly ascribable to the formation of delamination and cracks, which are influenced by the thermal stress during quenching process. The thermal stress $\left(\sigma_{\mathrm{R}}\right)$ mainly derived from the different thermal expansions. It can be described as (Ref 7): $\sigma_{\mathrm{R}} \approx \Delta \alpha \cdot \Delta T \cdot E_{\mathrm{f}} /$ $\left(1-v_{t}\right)$, where $\Delta \alpha$ is thermal expansion coefficient different between the coat and substrate, $\Delta T$ is the temperature change, $E_{\mathrm{f}}$ and $v_{\mathrm{t}}$ are the elastic modulus and Poisson's ratio of the coat material, respectively. The TEC values of the sample parts are in the order of $\mathrm{TEC}_{\text {Sub }}>\mathrm{TEC}_{\mathrm{Al}}>\mathrm{TEC}_{\mathrm{BC}}>\mathrm{TEC}_{\mathrm{YSZ}}$ (Fig. 8). After preparing $\mathrm{Al}$ interlayer, the stress between substrate and bond coat could be reduced. However, there are also stresses derived from different thermal expansion between Al layer and substrate, Al layer and bond coat. These two shear stresses with opposite direction are distributed in $\mathrm{Al}$ layer during thermal shock test. The stresses are parallel to substrate. There is few interlock between Al layer and substrate. Furthermore, owing to the low hardness and strength of Al layer, and existence of micropores or horizontal microcracks in Al layer, the sprayed Al interlayer is prone to failure. Therefore, the samples with sprayed $\mathrm{Al}$ interlayer have short cycle life in thermal shock test (about 3 cycles). The failure mainly occurs in Al layer and the interface between Al layer and substrate.

When quenched into different coolant, the directly sprayed sample and the sample with $\mathrm{Mg}$-Al diffused interlayer showed different thermal shock cycles. It is possible that the thermal shock resistance of them is affected not only by the coat structure but also by the interface properties. In order to explore the failure mechanism of the APS TBCs on Mg alloy, the directly sprayed sample and the sample with $\mathrm{Mg}$-Al diffused interlayer were also quenched from $300{ }^{\circ} \mathrm{C}$ into cold water and anhydrous ethanol, respectively. The results are shown in Fig. 13. Compared with quenching from $400{ }^{\circ} \mathrm{C}$, the cycle life of the samples increases. It is mainly due to that the thermal stress is reduced under low heated temperature. In addition, when quenched into water from 300 or $400{ }^{\circ} \mathrm{C}$, the thermal shock resistance of the sample with $\mathrm{Mg}-\mathrm{Al}$ diffused interlayer is significantly improved compared with directly sprayed sample. It could be considered that the thermal shock resistance of TBCs on Mg alloy

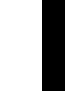


substrate is mainly related to the following factors: the oxidation and corrosion of substrate, interlocked interface and the TEC match of the components. The relationship between these factors and bond properties is confirmed according to the investigation of the failure mechanism.

The substrate surface morphologies of the failed samples are shown in Fig. 14. The substrate surface of the directly sprayed sample after failing in the thermal shock test (quenched from $400{ }^{\circ} \mathrm{C}$ into water) is coarse. There

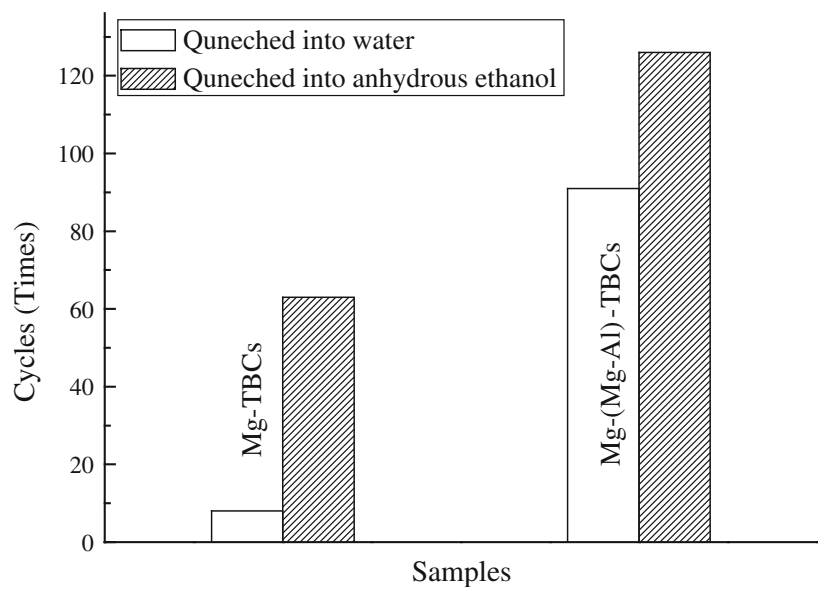

Fig. 13 Thermal shock test results of the samples after quenching from $300{ }^{\circ} \mathrm{C}$ to room temperature are many small particles (Fig. 14a). The XRD analysis indicates that the substrate was corroded during quenching into water. Some corrosion products $(\mathrm{MgO})$ are generated (Fig. 15). It could be considered that the failure procedure is composed of corrosion process and thermal stress failure. Once the specimen is quenched into the cold water, thermal stress is accumulated in the interface between substrate and bond coat. And then, microcracks would emerge at the interface. As the water contacting the substrate through the microcracks in the interface, the exposed substrate would be corroded. The corrosion of substrate reduces the bond strength of coat. Moreover, the growth of corrosion products has a volume expansion, which would accelerate the peeling of the coats. When the bond strength of the coat could not suffer the stress generated by the expansion mismatch and substrate corrosion, the coat would peel off. Thus, the failure of the sample occurs at the interface between substrate and bond coat (Fig. 14a). The corrosion products spread all over substrate surface. It suggests that the corrosion of substrate is rapid, and it finally causes the coat debonding.

The substrate surface of the directly sprayed sample after failing in the thermal shock test (quenching from $400{ }^{\circ} \mathrm{C}$ into anhydrous ethanol) shows tidy morphology. Clear craters distribute on the surface. XRD analysis shows that no obvious corrosion or oxidation occurred during quenching into anhydrous ethanol (Fig. 15). The failure of the coats mainly due to that the thermal stress concentration occurs in the interface. The creeps of
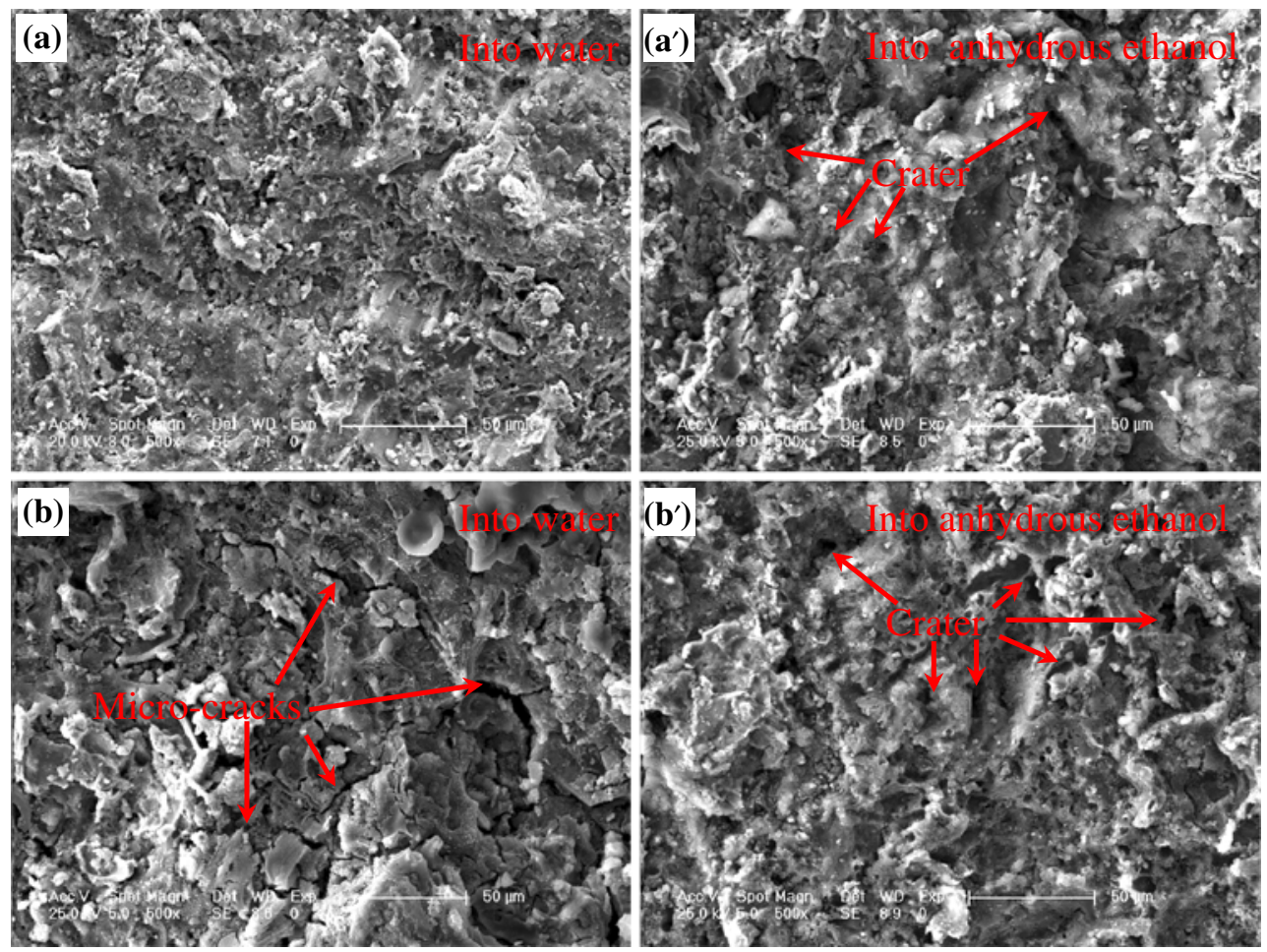

Fig. 14 Substrate surface morphologies of the failed samples after quenching from $400{ }^{\circ} \mathrm{C}$ into different coolant. (a, $\left.\mathrm{a}^{\prime}\right) \mathrm{MB} 26 / \mathrm{BC} / 8 \mathrm{YSZ}$ quenched into water and anhydrous ethanol, respectively. (b, $\left.\mathrm{b}^{\prime}\right) \mathrm{MB} 26 / \mathrm{Mg}-\mathrm{Al}$ (diffused)/BC/8YSZ quenched into water and anhydrous ethanol, respectively 


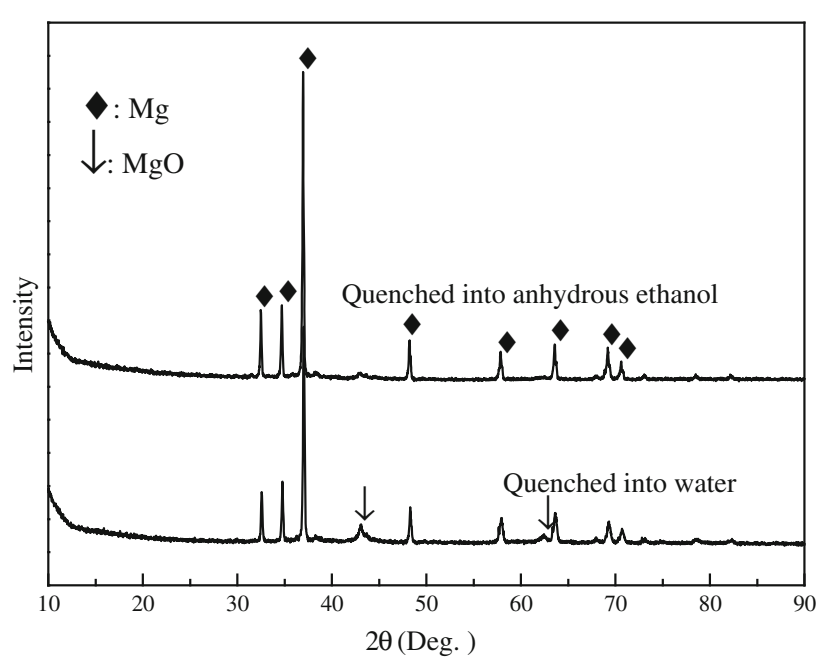

Fig. 15 XRD spectrums of substrate surface of the failed MB26/ $\mathrm{BC} / 8 \mathrm{YSZ}$ after quenching from $400{ }^{\circ} \mathrm{C}$ into different coolant

substrate and bond coat make the mechanical occlusion dissociate. The failure occurs at the interface between substrate and bond coat (Fig. 14a'). Accordingly, the failure of the coat is mainly controlled by the thermal stress and the bond status. The interlock between bond coat and substrate could improve the thermal shock resistance of the coat. While the TEC mismatch, temperature different and the oxidation of substrate during APS have an adversely affect on the thermal shock resistance of the coat.

After preparing $\mathrm{Mg}$-Al diffused interlayer, the thermal shock resistance of the TBCs on $\mathrm{Mg}$ alloy is significantly improved, whether quenched into water or anhydrous ethanol. As discussed above, the corrosion of substrate and thermal stress in interface are the main reasons that lead the failure of the TBCs on $\mathrm{Mg}$ alloy during quenching into water. $\mathrm{Mg}-\mathrm{Al}$ diffused layer is integrated with substrate. $\mathrm{Mg}$-Al diffused layer is well interlocked with bond coat. $\mathrm{TEC}_{\text {Sub }}>\mathrm{TEC}_{\mathrm{Mg}-\mathrm{Al}}>\mathrm{TEC}_{\mathrm{BC}}$. With the presence of $\mathrm{Mg}$-Al diffused interlayer, the stress between substrate and bond coat could be reduced. In addition, as shown in Fig. 16, Mg-Al diffused layer has a more positive potential than $\mathrm{Mg}$ alloy substrate $\left(\phi_{\mathrm{Mg}-\mathrm{Al}}\right.$ diffused layer $\left.>\phi_{\mathrm{MB} 26}\right)$. It means that $\mathrm{Mg}-\mathrm{Al}$ diffused layer has better corrosion resistance than $\mathrm{Mg}$ alloy. The well interlocked interface, small stress and the excellent corrosion resistance of substrate make the thermal shock resistance of the TBCs on $\mathrm{Mg}$ alloy improve during quenching into water. The substrate surface of the sample with $\mathrm{Mg}$-Al diffused interlayer after failing in the thermal shock test (quenching from $400{ }^{\circ} \mathrm{C}$ into water) is shown in (Fig. 14b). There are corrosion products and microcracks distributed in substrate surface. The $\mathrm{Mg}$-Al diffused layer has small corrosion rate. The corrosion products were slowly accumulated during the long cycle time showing large block. The well interlocked interface could suffer large stress. The $\mathrm{Mg}$ - $\mathrm{Al}$ diffused layer has high hardness. It could well withstand the creeps. Once the stress, which generated by the expansion mismatch and substrate corrosion, is large enough, $\mathrm{Mg}-\mathrm{Al}$ diffused layer could crack under the shear stress.

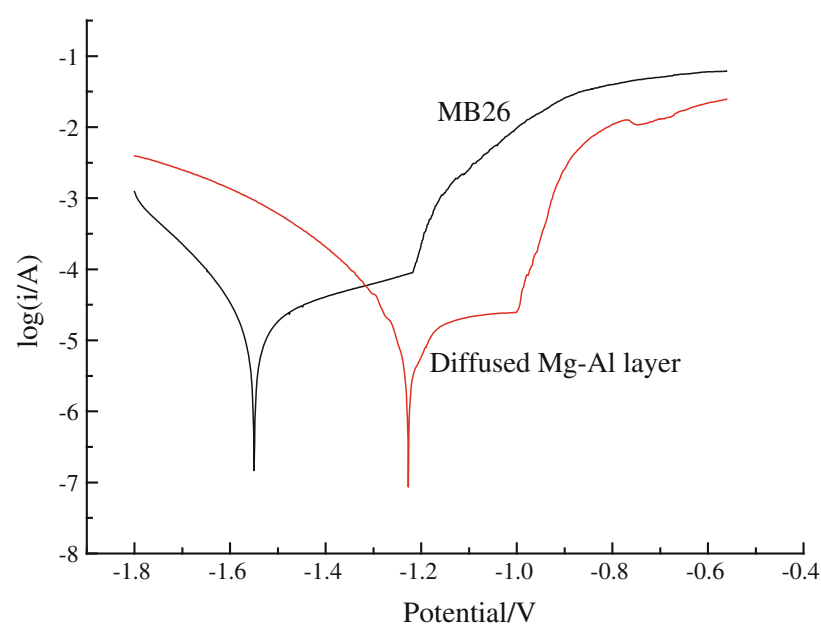

Fig. 16 Potentiodynamic polarization curves in 3.5 wt. $\% \mathrm{NaCl}$ solution for MB26 alloy and $\mathrm{Mg}-\mathrm{Al}$ diffused layer

The substrate surface of the sample with Mg-Al diffused interlayer after failing in the thermal shock test (quenching from $400{ }^{\circ} \mathrm{C}$ into anhydrous ethanol) is shown in Fig. 14( $\left.b^{\prime}\right)$. The substrate surface has similar morphology with the directly sprayed sample after quenching into anhydrous ethanol (Fig. 14a'). But deeper craters emerge in $\mathrm{Mg}$ - $\mathrm{Al}$ diffused layer. The substrate surface roughness of the sample was evaluated. The roughness of $\mathrm{Mg}-\mathrm{Al}$ diffused layer surface is $4.16 \pm 0.11 \mu \mathrm{m}$. And the roughness of $\mathrm{Mg}$ alloy substrate surface is $3.43 \pm 0.21 \mu \mathrm{m}$. Evidently, $\mathrm{Mg}$-Al diffused layer improves the interlock between bond coat and substrate. The results are consistent with the morphologies as shown in Fig. 14( $\left.\mathrm{a}^{\prime}\right)$ and $\left(b^{\prime}\right)$. The failure of the coat mainly derives from the thermal stress in interface. $\mathrm{Mg}$-Al diffused layer has high hardness and well interlocked interface with bond coat. The thermal stress in the interface between substrate and bond coat is smaller compared with directly sprayed sample. $\mathrm{Mg}$-Al diffused layer could well endure the creeps from the gradual accumulated shear stress. The failure of the coat is processed in form of dissociation between bond coat and $\mathrm{Mg}-\mathrm{Al}$ diffused layer, instead of intergranular embrittlement of $\mathrm{Mg}$ - $\mathrm{Al}$ diffused layer.

On the basis of the discussion of the failure mechanism of the samples in quenching process, the thermal shock resistance of TBCs on Mg alloy is affected by the coat structure, TEC match, bond status, and stability of substrate surface. The sprayed (AS or APS) Al layer has low hardness and defects in layer. It is prone to fail under thermal stress. After the deposition of sprayed $\mathrm{Al}$ layer, the thermal shock resistance is not improved. $\mathrm{Mg}-\mathrm{Al}$ diffused layer is integrated with substrate. It has low melting point which leads to well interlock with bond coat. $\mathrm{Mg}$ - $\mathrm{Al}$ diffused layer reduces the TEC mismatch between substrate and bond coat. Furthermore, $\mathrm{Mg}-\mathrm{Al}$ diffused layer improves the corrosion resistance of $\mathrm{Mg}$ alloy substrate. Therefore, $\mathrm{Mg}$-Al diffused layer significantly improves the thermal shock resistance of TBCs on Mg alloy substrate. 


\section{Conclusions}

Sprayed (AS or APS) Al and diffused $\mathrm{Mg}$-Al layers were prepared as interlayer between TBCs and Mg alloy substrate. The preparation and performances of the interlayer were investigated. The main conclusions are following:

(1) The sprayed (AS or APS) Al layer is compactly bonded with $\mathrm{Mg}$ alloy substrate and APS bond coat. Many horizontal microcracks distribute in AS Al layer. There is diffusion between AS Al layer and substrate after heat treatment at $200{ }^{\circ} \mathrm{C}$ for $2 \mathrm{~h}$. Few micropores emerge in APS Al layer. There is diffusion between APS Al layer and substrate during APS. The low hardness of $\mathrm{Al}$ layer and the defects in $\mathrm{Al}$ layer make the $\mathrm{Al}$ interlayer prone to fail under tensile or shear stress during tensile test and thermal shock test. Sprayed Al interlayer hardly improves the bond stability of TBCs on $\mathrm{Mg}$ alloy.

(2) $\mathrm{Mg}-\mathrm{Al}$ diffused layer is prepared by heat treatment of the sprayed sample (APS $\mathrm{Al}$ coat on $\mathrm{Mg}$ alloy) at $400{ }^{\circ} \mathrm{C}$. $\mathrm{Mg}$ - $\mathrm{Al}$ diffused layer is mainly composed of $\mathrm{Al}_{12} \mathrm{Mg}_{17}$. $\mathrm{Mg}$-Al diffused layer has lower melting point than $\mathrm{Mg}$ alloy substrate. $\mathrm{Mg}$-Al diffused layer can increase the occlusion between substrate and bond coat. The bond strength of TBCs on $\mathrm{Mg}$ alloy substrate with $\mathrm{Mg}-\mathrm{Al}$ diffused interlayer is only slightly increased due to the intergranular embrittlement of $\mathrm{Mg}-\mathrm{Al}$ intermetallic compound under tensile stress. $\mathrm{Mg}-\mathrm{Al}$ diffused layer is integrated with substrate. It has high hardness and moderate TEC. Besides, $\mathrm{Mg}-\mathrm{Al}$ diffused layer improves the corrosion resistance of $\mathrm{Mg}$ alloy substrate. Thermal shock resistance of TBCs on $\mathrm{Mg}$ alloy is mainly affected by the corrosion resistance of substrate or the thermal stress in bond interface. After the preparation of $\mathrm{Mg}$ - $\mathrm{Al}$ diffused interlayer, the thermal shock resistance of TBCs on $\mathrm{Mg}$ alloy substrate is significantly improved. The findings of this study are important for applications such as automotive, aerospace, medical implants, etc.

\section{Acknowledgments}

Financial support from projects of NSFC-21171160, NSFC-51101143 and Lotus Scholars Program of Hunan are gratefully acknowledged.

\section{References}

1. S. Ishihara, H. Notoya, A. Okada, Z.Y. Nan, and T. Goshima, Effect of Electroless-Ni-Plating on Corrosion Fatigue Behavior of Magnesium Alloy, Surf. Coat. Technol., 2008, 202, p 2085-2092

2. Y. Kojima, Handbook Advanced Magnesium Technology, Kallos Publishing, Tokyo, 2000
3. J.E. Gray-Munro, B. Luan, and L. Huntington, The Influence of Surface Microchemistry in Protective Film Formation on MultiPhase Magnesium Alloys, Appl. Surf. Sci., 2008, 254, p 2871-2877

4. E. Aghion, B. Bronfin, and D. Eliezer, The Role of Magnesium Industry in Protecting the Environment, J. Mater. Process Technol., 2001, 117, p 381-385

5. H. Friedrich and S. Schumann, Research for a "New Age of Magnesium" in the Automotive Industry, J. Mater. Process Technol., 2001, 117, p 276-281

6. J.E. Gray and B. Luan, Protective Coatings on Magnesium and Its Alloys-A Critical Review, J. Alloys Compd., 2002, 336, p 88-113

7. Z.H. Xu, S.M. He, L.M. He, R.D. Mu, G.H. Huang, and X.Q. Cao, Novel Thermal Barrier Coatings Based on $\mathrm{La}_{2}\left(\mathrm{Zr}_{0.7}\right.$ $\left.\mathrm{Ce}_{0.3}\right)_{2} \mathrm{O}_{7} / 8 \mathrm{YSZ}$ Double-Ceramic-Layer Systems Deposited by Electron Beam Physical Vapor Deposition, J. Alloys Compd., 2011, 509, p 4273-4283

8. C.G. Levi, Emerging Materials and Processes for Thermal Barrier System, Curr. Opin. Solid State Mater. Sci., 2004, 8, p 77-91

9. Z.H. Xu, L.M. He, R.D. Mu, F. Lu, S.M. He, and X.Q. Cao, Thermal Cycling Behavior of YSZ and $\mathrm{La}_{2}\left(\mathrm{Zr}_{0.7} \mathrm{Ce}_{0.3}\right)_{2} \mathrm{O}_{7}$ as Double-ceramic-layer Systems EB-PVD TBCs, J. Alloys Compd., 2012, 525, p 87-96

10. X.Z. Fan, Y.J. Liu, Z.H. Xu, Y. Wang, B.L. Zou, L.J. Gu, C.J. Wang, X.L. Chen, Z.S. Khan, D.W. Yang, and X.Q. Cao, Preparation and Characterization of 8YSZ Thermal Barrier Coatings on Rare Earth-Magnesium Alloy, J. Therm. Spray Technol., 2011, 20, p 948-957

11. K. Kokini, J. DeJonge, S. Rangaraj, and B. Beardsley, Thermal Shock of Functionally Graded Thermal Barrier Coatings with Similar Thermal Resistance, Surf. Coat. Technol., 2002, 154, p 223-231

12. M. Yamanouchi, M. Koizumi, T. Hirai, and I. Shiota, Functionally Graded Materials Forum, Proceedings of the First International Symposium on Functionally Graded Materials (FGM'90), Sendai, Japan, 1990

13. K.A. Khor, Z.L. Dong, and Y.W. Gu, Plasma Sprayed Functionally Graded Thermal Barrier Coatings, Mater. Lett., 1999, 38, p 437-444

14. Y.C. Xin, K.F. Huo, T. Hu, G.Y. Tang, and P.K. Chu, Mechanical Properties of $\mathrm{Al}_{2} \mathrm{O}_{3} / \mathrm{Al}$ Bi-Layer Coated AZ91 Magnesium Alloy, Thin Solid Films, 2009, 517, p 5357-5360

15. M. Carboneras, M.D. López, P. Rodrigo, M. Campo, B. Torres, E. Otero, and J. Rams, Corrosion Behaviour of Thermally Sprayed $\mathrm{Al}$ and $\mathrm{Al} / \mathrm{SiC}$ Composite Coatings on ZE41 Magnesium Alloy in Chloride Medium, Corros. Sci., 2010, 52, p 761-768

16. M. Campo, M. Carboneras, M.D. López, B. Torres, P. Rodrigo, E. Otero, and J. Rams, Corrosion Resistance of Thermally Sprayed $\mathrm{Al}$ and $\mathrm{Al} / \mathrm{SiC}$ Coatings on $\mathrm{Mg}$, Surf. Coat. Technol., 2009, 203, p 3224-3230

17. K. Spencer, D.M. Fabijanic, and M.X. Zhang, The Use of $\mathrm{Al}-\mathrm{Al}_{2} \mathrm{O}_{3}$ Cold Spray Coating to Improve the Surface Properties of Magnesium Alloys, Surf. Coat. Technol., 2009, 204, p 336-344

18. M.F. He, L. Liu, Y.T. Wu, C. Zhong, and W.B. Hu, Influence of Microstructure on Corrosion Properties of Multilayer $\mathrm{Mg}-\mathrm{Al}$ Intermetallic Compound Coating, Corros. Sci., 2011, 53, p $1312-1321$

19. Y.P. Ma, K.W. Xu, W.X. Wen, X.P. He, and P.F. Liu, The Effect of Solid Diffusion Surface Alloying on Properties of ZM5 Magnesium Alloy, Surf. Coat. Technol., 2005, 190, p 165-170

20. K. Spencer and M.X. Zhang, Heat Treatment of Cold Spray Coatings to Form Protective Intermetallic Layers, Scripta Mater., 2009, 61, p 44-47

21. G.L. Song, A. Atrens, X.L. Wu, and B. Zhang, Corrosion Behaviour of AZ21, AZ501 and AZ91 in Sodium Chloride, Corros. Sci., 1998, 40, p 1769-1791

22. C. Brubaker, Z.K. Liu, and A.A. Luo, Ed., Magnesium Technology 2004, Minerals, Metals and Materials Society/AIME, Warrendale, 2004, p 229

23. P. Villars and L.D. Calvert, Ed., Pearson's Handbook of Crystallographic Data for Intermetallic Phases, ASM International, Materials Park, OH, 1991 